\title{
Correction to: Serum CA19-9 Response to Neoadjuvant Therapy Predicts Tumor Size Reduction and Survival in Pancreatic Adenocarcinoma
}

\author{
Amr I. Al Abbas, MD ${ }^{1,2}$, Mazen Zenati, MD, $\mathrm{PhD}^{1}$, Caroline J. Rieser, MD ${ }^{1}$, Ahmad Hamad, MD ${ }^{1,3}$, \\ Jae Pil Jung, MD ${ }^{1,4}$, Amer H. Zureikat, MD ${ }^{1}$, Herbert J. Zeh III, MD ${ }^{1,2}$, and Melissa E. Hogg, MD ${ }^{1,5}$ \\ ${ }^{1}$ University of Pittsburgh, Pittsburgh, PA; ${ }^{2}$ University of Texas Southwestern, Dallas, TX; ${ }^{3}$ Ohio State University, \\ Columbus, OH; ${ }^{4}$ Andong Medical Group Hospital, Andong-si, Gyeongbuk, Korea; ${ }^{5}$ Walgreens Building, Department of \\ Surgery 2539, Northsore University HealthSystem, Evanston, IL
}

CORRECTION TO: ANN SURG ONCOL

HTTPS://DOI.ORG/10.1245/S10434-019-08156-3

In the original article, Caroline J. Rieser's last name is spelled wrong. It is correct as reflected here.

The original article can be found online at https://doi.org/10.1245/ s10434-019-08156-3.

(C) Society of Surgical Oncology 2020

Published Online: 7 February 2020

M. E. Hogg, MD

e-mail: MHogg@Northshore.org 